\title{
Modernidade e diversidade cultural: o limite é o mercado - um estudo de caso sobre o artesanato de capim-dourado no Jalapão
}

\author{
Thais Alves Marinho \\ Doutora em Sociologia (Universidade de Brasília) \\ Professora de Sociologia da PUC-GOIÁS \\ Goiânia, Goiás, Brasil \\ thais_marinho@hotmail.com
}

Resumo Este artigo visa discutir, num ambiente de diversidade cultural, como o anacronismo identitário atual, após frustrar a linearidade racionalista da modernidade, em vez de deflagrar a decadência desse pretenso sistema universalista se rearticula aos seus parâmetros, por meio do mercado e das conectividades técnico-informacionais. A análise gira em torno de um estudo de caso sobre os conflitos sociais e identitários entre os atores envolvidos na produção de artesanato de capim- dourado, na região do Jalapão, no Tocantins. O sucesso do artesanato desse capim, tanto em âmbito nacional quanto internacional, reflete o retorno às tradições e à valorização cultural, que pode ser compreendido como uma tentativa de preencher o vácuo deixado pela perda da transcendentalidade da cultura no ambiente de desencaixe da modernidade globalizada atualmente. Tais embates nos permitem compreender como a valorização cultural e identitária pelo mercado pode significar a satisfação da dignidade e do bem-estar social dos artesãos de capim-dourado pela superação da inclusão periférica na economia. Essa valorização ainda alavanca o desenvolvimento local, enquanto desencadeia novos conflitos.

Palavras-chave: desenvolvimento local, economia criativa, modernidade, diversidade cultural.

\section{Introdução}

A atual organização da produção e comercialização de artesanato

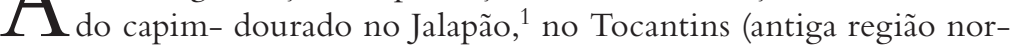
te de Goiás), é elucidativa dos conflitos inaugurados e desencadeados pela modernidade no Brasil, especialmente no tocante às concepções de desenvolvimento nacional. $\mathrm{Na}$ atualidade, esse saber tradicional tem sido reapropriado pelo mercado em âmbito nacional e internacional, após décadas de esquecimento e desvalorização, já que a expectativa de progresso nacional esteve associada até então à produção de mão de obra para as crescentes indústrias (Fernandes, 1972). Aqueles jalaponenses que não migraram em direção às grandes cidades, se integrando à sociedade de classes e satisfazendo os apelos do progresso nacional, se ampararam nesse conhecimento sociotécnico de manejo da natureza.

1. Atualmente a região do Jalapão é formada por oito municípios do Estado do Tocantins: Ponte Alta do Tocantins, São Félix do Tocantins, Lizarda, Santa Tereza do Tocantins, Lagoa do Tocantins, Novo Acordo, Rio Sono e Mateiros. 
Este se tornou o vínculo das construções simbólicas locais, fundamentando o sentido de comunidade e territorialidade desses artesãos, descendentes de índios e negros, que durante todo o século XX estiveram deslocados no tempo e no espaço diante dos anseios racionalistas e universalistas da crescente economia de mercado e, por isso, se tornaram emblema do atraso, do sertão, da periferia.

Isso porque o advento da modernidade inaugurou uma nova forma de organização social, pautada em ideais universalistas, que se sustentava em uma concepção individualista e racionalista de indivíduo e sociedade (Rouanet, 1993). A institucionalização desses ideais pelo Estado Moderno passa a gerir de forma utilitária as práticas, os costumes, as crenças e as identidades sociais nos diversos campos da vida, acirrando um movimento histórico e estrutural que alavanca a reprodução do modo de produção capitalista pela despolitização da esfera pública, como avalia Habermas (1962). Nessa lógica, a cultura perderia sua transcendentalidade e se tornaria mais um capital, uma reserva, um recurso, gerida por gestores sociais que visam não só à construção de uma identidade nacional, mas também à complementação do desenvolvimento econômico, ao transformarem atividades sociais em propriedades intelectuais e patrimônios da humanidade (Canclini, 1993).

Esse sistema ideológico e econômico tem como marca a desigualdade combinada, já que é permeado por heterogeneidades e hierarquizações entre forças nacionais e internacionais, dominantes e dominadas, centro e periferia, urbano e rural, civilizado e atrasado. Essa dualidade aparentemente delimitada, no entanto, ao se objetivar propõe transformações inesperadas, já que tais instâncias são articuladas, enquanto corpos constituidores de uma mesma estrutura inter-relacionada obrigatoriamente pela esfera do mercado e pela instantaneidade tecnológica dos meios de comunicação e de transportes (Santos, 2002).

Apesar dessa articulação, nesse ambiente de aprofundamento da integração econômica, política e social, impera a desigualdade enquanto marca estrutural (Friedman, 1985). Os embates entre as diferenças de saberes, acessos, práticas, discursos, identidades, lógicas impedem uma compreensão universal da cultura eleita enquanto universal. A gestão de suas diretrizes cognitivo-instrumental, prática-moral e estética expressiva, utilizadas como estratégias geopolíticas e ideológicas de homogeneização da racionalidade moderna, não consegue afastar a perspectiva metafísico-religiosa transmitida tanto pela herança grega e judaica quanto pela herança afro-indígena, inseridas no cristianismo latino; tampouco consegue afastar a cultura e as tradições locais das crenças e das práticas individuais e comunitárias, formando um "self pontual" (Taylor, 1997) adaptado a condutas metódicas de vida. A esses grupos tradicionais resistentes, como os jalaponenses, restam a desvalorização no mercado de trabalho e a ausência ou falso reconhecimento de suas identidades (Taylor, 1998); por isso, em muitos casos, constituem guetos de sobrevivência, onde o território se torna o fundamento de suas construções simbólicas (Yúdice, 2006).

Tal desencontro de nexos na regulação das ações individuais e grupais tem sido tratado numa visão reducionista em termos de exclusão ou marginalização social, ignorando os diversos embates e conflitos fundados ora em elementos ontológicos (identitários), ora em outros de cunho lógico-formal, ou virtual, ou territorial protagonizados por tais grupos. Assim, mesmo que de forma periférica, como já alertara José de Souza Martins (1997), esses grupos e indivíduos constroem e criam formas próprias de inclusão, utilizando os meios ofertados pelo próprio sistema que os oprime, como avalia Lifschitz (2011), ao tentar compreender o fenômeno das neocomunidades. Logo, a integração transcultural, possibilitada pelo intenso fluxo de pessoas, bens, saberes e serviços, contribui, na realidade, para uma ressemantização dos limites entre tempo e espaço de comunidades locais. Essa realidade possibilita que protestos isolados se encontrem e constituam redes de movimentos de resistência e contracultura, que explicitam lógicas de atuação e concepções de mundo muito distintas das expectativas racionalistas do estado e da economia, o que acirra os conflitos sociais (Martin-Barbero, 2004).

Esse anacronismo identitário (pautado nas particularidades, sejam identitárias, culturais, territoriais etc.), após frustrar a linearidade racionalista da modernidade, em vez de deflagrar a decadência desse pretenso sistema universalista se rearticula aos seus parâmetros, especialmente pelas conectividades técnico-informacionais, e se impõe de modo a constituir suas novas diretrizes (Ortiz, 2003).

Tal absorção prosaica das identidades e culturas locais no movimento global, como salienta Yúdice (2006), se manifesta nas concepções de agenciamentos, empoderamentos, empreendedorismo e performatividades, e demonstra sua aceitação formal pelas agências globais e estatais (Rubim; Rocha, 2012), que agora discursam pela preservação das tradições como forma de manter a biodiversidade e como fonte de inovação que alavanca o capital e o mercado, fundamentando o setor da Economia Criativa. ${ }^{2}$

2. Esse setor está relacionado aos desdobramentos da Indústria cultural a partir da década de 1960, que visava aliar arte e economia de forma massificada. Esta definição restrita mostrou-se insuficiente, uma vez que os avanços nas tecnologias de informação e comunicação, softwares e, em particular, a rápida emergência e massificação da Internet tiveram um impacto significativo nestas atividades, não permitindo o seu enquadramento em nenhuma das categorias convencionais, o que as excluía do campo das artes e da cultura. O conceito de indústria criativa 
É nesse contexto de multiplicidade de subjetivações indissociáveis da tradição e dos localismos tomados agora como base para experimentação do desenvolvimento local, na medida em que se constituem como bens simbólicos que impulsionam o mercado nacional e internacional, que se inserem os conflitos aqui estudados. Tais embates giram em torno da gestão da territorialidade, da patrimonialização e do reconhecimento identitário, bem como da modernização e da mercantilização dos saberes e recursos seculares. O intuito deste trabalho, portanto, é compreender como esse momento de valorização cultural e identitária pelo mercado pode significar a satisfação da dignidade e do bem-estar social dos artesãos de capim-dourado pela superação da inclusão periférica na economia, alavancando o desenvolvimento local. Para tanto, realizo um estudo de caso em um dos municípios da região do Jalapão, Ponte Alta do Tocantins, para compreender como os conflitos travados pelos artesãos do capim-dourado visam combater as forças hegemônicas e hierarquizantes do mercado, garantindo a proteção de sua propriedade intelectual e identitária sobre os recursos naturais e sobre a produção e comercialização de seu artesanato.

\section{O desenvolvimento do capim-dourado no Jalapão}

A utilização do capim-dourado para o artesanato é secular, muitos indicam sua origem na tradição indígena. Os índios costuravam o capim-dourado com a seda de tucum para produzir utensílios domésticos, como suportes para panelas e cestas. Mas foi com a lendária Dona Miúda (in memoriam), cujo nome é Guilhermina Ribeiro da Silva, moradora do povoado de Mumbuca, no município de Mateiros, região norte do Estado de Goiás, ${ }^{3}$ que o artesanato do capim-dourado ganhou fama.

Dona Guilhermina nasceu em 1928, era filha de indígena com afrodescendente. Residentes na zona rural de Mateiros desde 1919, mantinham-se com a agricultura de subsistência e criação de animais de pequeno porte, como tantos outros grupos de negros rurais, agora chamados de "quilombolas". ${ }^{4}$ Desde pequena observava a arte de sua mãe, que produzia o que hoje chamamos de souplats, um suporte para panelas quentes, além de cestas para armazenar o algodão que seria fiado e depois tecido. Também faziam chapéus (Figura 1), usados para proteção contra o sol durante o manejo das roças. Quando ainda era moça e sua mãe já era falecida, Dona Miúda resolveu retomar o conhecimento adquirido quando criança, que se fixara como um rastro de recordação (Ricoeur, 1993), porque se encantava com a beleza do brilho do capim- dourado, como afirma sua filha "Detô". Logo, descobriu que a fibra da folha do buriti era melhor para costurar o capim, demonstrando a capacidade de atualização das tradições.

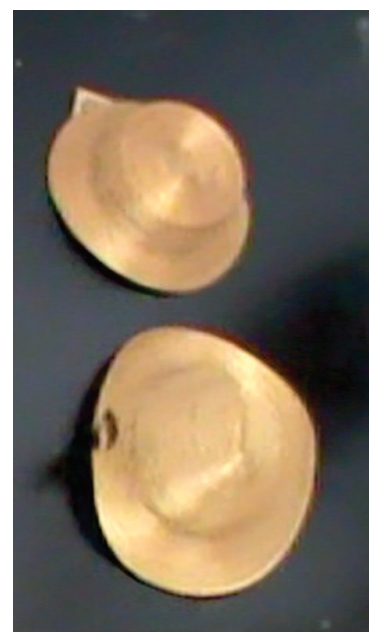

Figura 1 - Chapéu tradicional

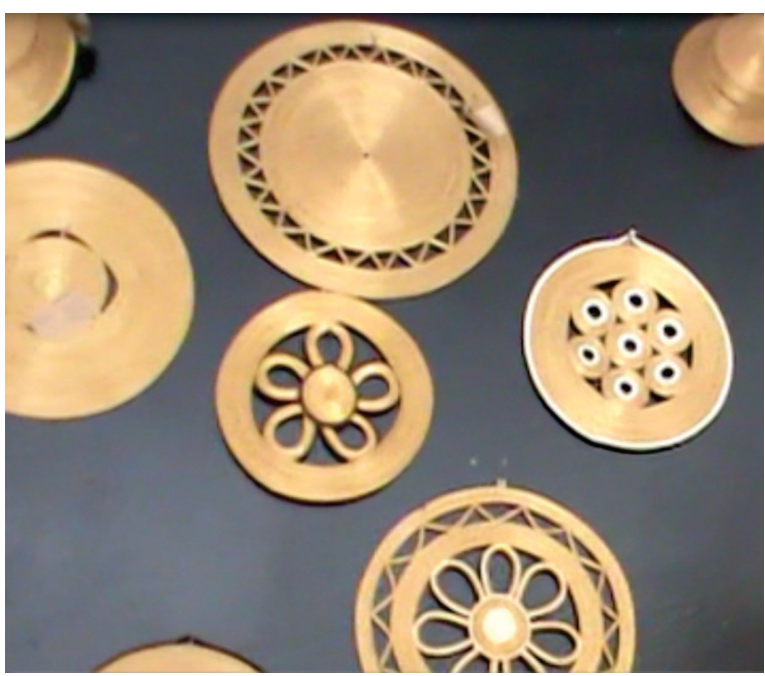

Figura 2 - Souplat

busca englobar essa categoria. Surge no início da década de 90, na Austrália, mas é no final desse período que obtém maior relevância ao ser inserido nas políticas definidas pelo Department for Culture, Media and Sport (DCMS) do Reino Unido, com a criação do Creative Industries Unit and Task Force, em 1997. No Creative Industries Mapping Document, as Indústrias Criativas são definidas como aquelas que têm a sua origem na criatividade, competências e talento individual, com potencial para a criação de trabalho e riqueza através da geração e exploração da propriedade intelectual. Ver: Howkins (2011) ou Alves (2012).

3. Após 1988, o Estado de Goiás é dividido, sendo que a região norte (onde estão localizados os municípios estudados) passa a constituir um novo Estado: Tocantins.

4. O quilombo Mumbuca foi certificado pela Fundação Cultural Palmares em 2006. 


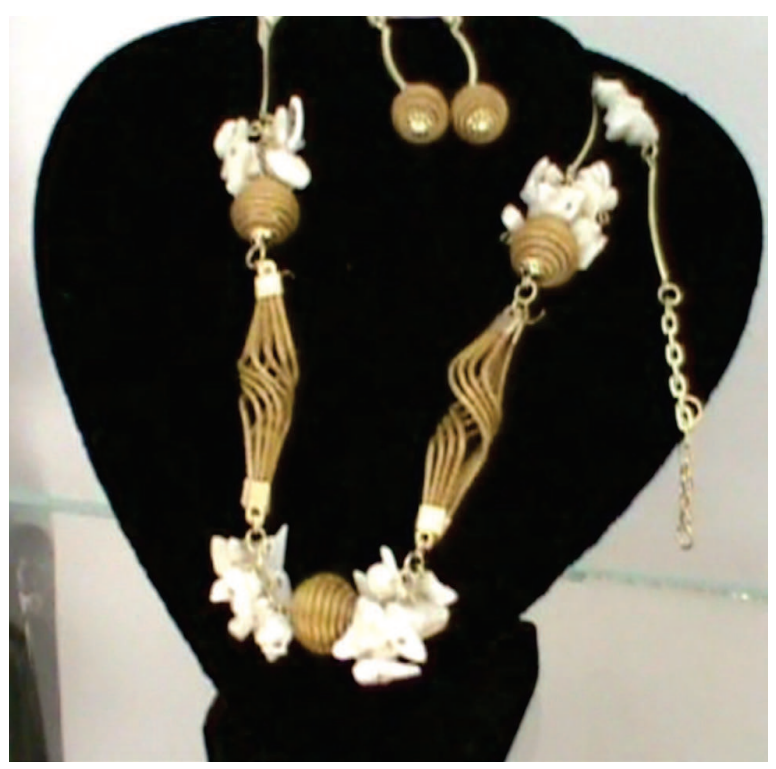

Figura 3 - Brinco e colar

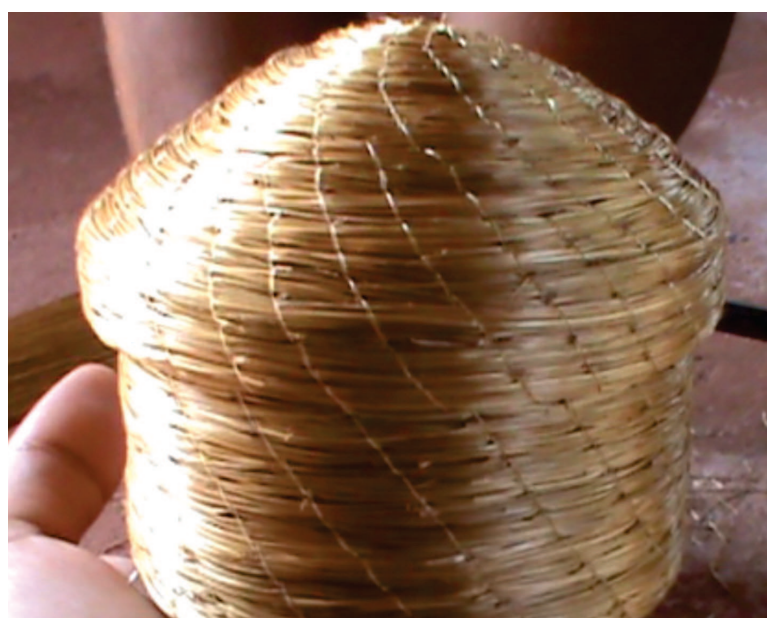

Figura 4 - Porta-trecos

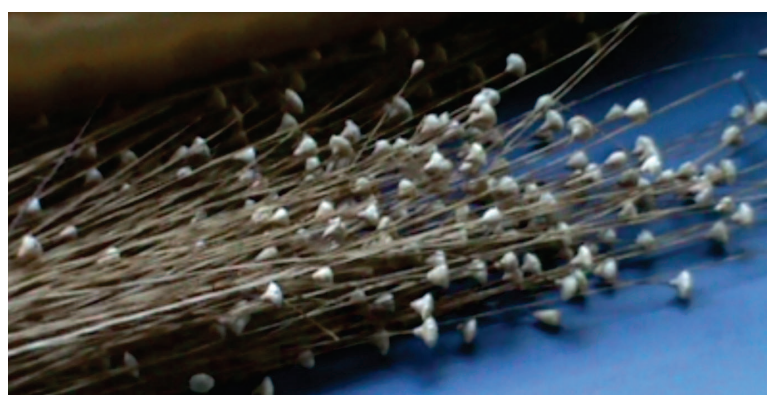

Figura 5 - Capim-dourado (in natura)

Percebemos que as paixões e sensos estéticos, de tão naturais e dinâmicos, se complexificam no processo de atualização e redimensionamento constante da memória, num persistente revisitamento e redirecionamento que ocorrem, por sua vez, de acordo com as arbitrariedades da dialética do tempo e dos acontecimentos, os quais articulam o que ficou per- dido com o que está acontecendo, com o que ainda virá.

Muitos entrevistados relataram que era comum o uso do chapéu nas roças, mas quando os camponeses iam às cidades conseguir mantimentos escondiam o adorno por vergonha e por medo dos comentários. Isso porque o chapéu valorizado na região era feito de couro, o que indicava o refinamento estético de seus usuários, enquanto o chapéu de capim-dourado acabava servindo como diacrítico da identidade afro-indígena, associada ao atraso e à selvageria. Essas estratégias de distinção social, como denuncia Bourdieu (2007), são fundadas numa estrutura relacional cujo foco está nas práticas de consumo cultural, primordialmente, e, marginalmente, nos fatores econômicos, já que em muitos casos os usuários de chapéu de couro viviam em condições financeiras semelhantes às dos grupos rurais.

Por outro lado, tais práticas distintivas, fundadas em diretrizes universalistas, condicionam o não reconhecimento das identidades particulares desses artesãos do capim dourado, gerando situações de discriminação, opressão, falta de oportunidades que geram ou a marginalização ou a inclusão periférica no sistema social. Tais tensões se manifestam na construção identitária em termos de insegurança, de sofrimento psíquico, de perturbações psicossomáticas, de depressões nervosas, stress, que levam à impossibilidade de emancipação e de autonomia individual, nos termos racionalistas.

Mas essa discriminação não incomodava Dona Miúda, isso porque, como afirma Taylor (1998), apesar de a ausência de reconhecimento institucional influenciar as identidades grupais pelo seu caráter dialógico, é a orientação e comunicação com nossos outros significantes (como a família) - mesmo quando estes desaparecem de nossas vidas - que definem a ontologia dessa identidade. Por isso, Dona Miúda passou a produzir, além dos itens que sua mãe fabricava, também bolsas, porta-moedas e miudezas. Quando ia ao Piauí e à Bahia, nas décadas de 1950 a 1990, para comercializar sua produção de farinha de mandioca e arroz, e comprar tecido, sal, óleo e outros utensílios, Dona Miúda levava seu artesanato, que era apreciado pela elite do lugar. Seus principais compradores eram fazendeiros e comerciantes, que usavam os objetos adquiridos para adornar suas residências. Logo, foi ensinando a seus filhos, sobrinhos e netos, que levaram o conhecimento a outros moradores do Jalapão.

Com a idade, Dona Miúda deixou de comercializar seus produtos fora do Mumbuca. A divisão de Goiás e a consequente emancipação do Estado do Tocantins, em 1988, possibilitaram que diversas instituições fossem formalizadas visando à ampliação da cidadania, para diferentes grupos e pessoas, e o 
desenvolvimento do novo estado que surgia. Houve melhorias na região, o que possibilitou aos moradores dispensar as longas idas a outros estados para adquirir recursos. Conseguiam ali mesmo, em Mateiros, ou mesmo em Palmas, a nova capital do Estado.

Em 1989 é criada a Fundação Natureza do Tocantins (Naturatins), em 1990 ocorre a criação do Serviço Brasileiro de Apoio às Micro e Pequenas Empresas do Tocantins (Sebrae-TO). Como consequência a região passou a adquirir maior visibilidade e atrair turistas, que se admiravam com o trabalho de Dona Miúda. O crescente turismo gerou a necessidade de preservação e patrimonialização, que se formaliza a partir de 2001, com a criação do Parque Estadual do Jalapão. Pela riqueza de seu bioma e por apresentar uma vasta área de cerrado contínuo e conservado, torna-se uma área de proteção ambiental Área de Proteção Ambiental (APA) do Jalapão, que se conecta ao sul com a Estação Ecológica Serra Geral do Tocantins, e ao norte com o Parque Nacional das Nascentes do Rio Parnaíba (criado em 2002, localizado na divisa dos estados do Piauí, do Maranhão, da Bahia e do Tocantins), ambos administrados pelo Instituto Chico Mendes de Conservação da Biodiversidade (ICMBio). Esse ambiente abriga cachoeiras, nascentes, dunas, chapadas, que se tornam atrativos para os turistas aventureiros, que vêm também em busca da cultura do local, especialmente entre os meses de junho e agosto, quando ocorrem os festejos de Ponte Alta.

O protagonismo de Dona Miúda logo fica conhecido, e em parceria com o Sebrae funda a Associação dos Artesãos de Capim-dourado de Mumbuca, em 2000, numa ação pioneira. Essa dinâmica da cultura local possibilita a revalorização do território e a reconstrução de práticas e saberes tradicionais, que ativam a memória para salvaguardar os resquícios do patrimônio material. Nesse processo, "agentes da modernidade", como o Sebrae, promovem a reconstrução simbólica e material de territórios comunitários e de saberes tradicionais por meio de técnicas e dispositivos modernos, assim como ocorre com as neocomunidades observadas por Lifschitz (2011). Assim, em vez de hibridação, como trata Canclini (1993), essas neocomunidades são reformuladas sobre seus territórios tradicionais, produzindo "autenticidades" culturais espacialmente e simbolicamente delimitadas e que ainda satisfazem as demandas de mercado.

À medida que o Parque do Jalapão atraía turistas, o artesanato foi sendo valorizado e sua produção estimulada pela crescente demanda. O sucesso da associação de Mumbuca se espalha pela região marcada pela vida árdua e ausente de oportunidades. Durante o Rally dos Sertões em 2001, que passou por Ponte Alta do Tocantins, o secretário de Turismo do município, Valtair Daniel, observou que havia demanda, por parte dos turistas, pelo artesanato que estava sendo exposto, embora não fosse comercializado na cidade. Apenas a filha caçula de Dona Miúda, Dalvanice, conhecida por Detô, que morava na região desde 1992, produzia e vendia para Palmas. Por intermédio de um parente, comercializava potes, porta-joias, souplats (Figura 2, acima), chapéus, bolsas, porta-trecos (Figura 4, acima), como sua mãe. O então secretário de turismo do município decidiu buscar ajuda junto ao Sebrae para a disseminação desse conhecimento.

O Sebrae patrocinou a ida de uma ex-moradora de Ponte Alta que se casara com um dos sobrinhos-netos de Dona Miúda, conhecido por Pelé, para ensinar o que havia aprendido com Dona Miúda quando estivera em Mumbuca. Dona Raimunda "de Pelé", como era conhecida, embora tenha resistido no início, decidiu ministrar o curso para 20 pessoas, mediante pagamento por seus serviços. Apenas 12 se formaram. Logo, a filha de Dona Miúda, Detô, residente em Ponte Alta, também passou a ensinar em sua casa, e cada um que aprendia ensinava outro, até que toda a cidade estava envolvida na produção do artesanato. A Associação de Ponte Alta foi formada a partir desse encontro, em 2002, e teve Dona Raimunda como primeira presidente. Depois de um breve mandato, ela abandonou o cargo e criou outra associação em Mateiros, onde residia.

Desde então, os associados de Ponte Alta participam periodicamente de cursos ofertados pelo Sebrae, de controle financeiro, técnicas de venda, design de bijuterias, manutenção do site criado pelo Sebrae para a associação, entre outros. A associação também se inscreve em editais públicos, como o Prêmio Dona Miúda, ofertado pela Secretaria de Cultura do Estado do Tocantins, visando obter financiamento para melhorias no empreendimento. O conhecimento e as verbas adquiridas geraram uma inovação no comércio e na produção do artesanato. Agora produzem, além dos produtos tradicionais, anéis, pulseiras, colares, presilhas de cabelo, porta-canetas, porta-joias, capim em tela, sendo criado constantemente um novo produto. $\mathrm{O}$ acesso à internet possibilitou a ampliação da venda e a exportação. Muitos pedidos são feitos por meio dessa mídia, que facilita a comunicação e a divulgação dos produtos. Os pedidos de países como Canadá, Estados Unidos, França, Itália, Espanha, Portugal são comuns e rotineiros. Outros estados do país também compram: Rio de Janeiro, São Paulo, Goiás, Santa Catarina, entre outros.

Tal realidade significa, como avalia Rubim (2012), que na contemporaneidade as relações entre cultura e economia não se restringem mais àquelas exercidas pelos mecenatos. As afinidades entre tais categorias passam agora a ser patrocinadas não de forma individual ou corporativa, como forma de defesa dos modelos de apropriação como ocorria no passado, 
mas associadas a um componente de marketing que elege a cultura como uma marca, que certifica não só a origem, mas também sua autenticidade. A regulação estatal sobre esse processo é aos poucos transferida para o financiamento privado, com a criação de leis de incentivo à cultura, que se fundamentam no resgate da tradição por meio de técnicas modernas.

\section{A organização e os conflitos do artesanato do capim-dourado}

A organização do artesanato de capim-dourado em Ponte Alta do Tocantins revolucionou a cidade, que passou a ser agraciada com melhorias em vários âmbitos estruturais e logísticos, como a construção de estradas, acesso à internet e telefonia móvel, infraestrutura para atendimento aos turistas, entre outras melhorias. O crescente interesse pelo local e pelo artesanato, por parte da sociedade civil - como turistas, comerciantes, acadêmicos, pesquisadores, jornalistas, "ongueiros" (pessoas que trabalham ou administram ONG) -, advém de uma combinação única entre tradição, criatividade, recursos naturais, empreendedorismo, turismo e festejos.

O principal parceiro da Associação dos Artesãos de Capim-Dourado Pontealtense é o Sebrae, que oferece periodicamente consultorias e reconhecimento institucional, por meio do Prêmio Top 100, por exemplo. Em 2011, por meio de um convênio com o Sebrae, a associação recebeu orientação de Marcelo Rosenbal, arquiteto do Programa Caldeirão do Huck, que criou uma coleção de sua autoria para a associação, a Coleção Jalapa. O material é reproduzido pelos artesãos e vendido pela associação sem a necessidade de pagamento de direitos autorais.

A Prefeitura Municipal de Ponte Alta oferece apoio logístico, cedendo espaço para a sede da associação, e a Secretaria de Cultura do Estado do Tocantins oferece apoio financeiro por meio de prêmios e editais, como o Prêmio Dona Miúda, de 2012. A organização não governamental Pesquisa e Conservação do Cerrado (PEQUI) e a Naturatins oferecem reconhecimento institucional e consultorias sobre o manejo e a extração sustentável do capim-dourado, por meio de oficinas e cursos de capacitação. A Agência de Desenvolvimento Sustentável do Jalapão oferece apoio financeiro e logístico, por meio de editais do Ministério do Desenvolvimento Agrário. Além disso, os governos estadual e federal patrocinaram a construção ou reforma de estradas de acesso, diminuindo as distâncias entre a região e a capital do Estado, oferecendo o mínimo de infraestrutura necessária para o desenvolvimento local.
O sucesso da comercialização do capim-dourado não só ampliou as possibilidades de sobrevivência, como também permitiu o acesso dos moradores a novos saberes, novos bens, novas tecnologias, novos padrões estéticos e éticos, novas oportunidades, novos horizontes, mas também novos conflitos. Agora, existem conflitos burocráticos, relativos à administração dos recursos financeiros, à comercialização do artesanato e à produção local; mas também existem conflitos identitários, relativos aos direitos de propriedade intelectual, de exploração do capim-dourado e de massificação dos saberes tradicionais. Os conflitos se iniciam, portanto, desde a extração e distribuição da matéria-prima até a organização, comercialização e distribuição da produção dos artesanatos.

O protagonismo da associação na gestão da produção sempre foi motivo de controvérsias, isso porque os artesãos tradicionalmente produzem de forma individualizada e autônoma, com base numa lógica de subsistência familiar, que não visa apenas o lucro, como na lógica capitalista, mas também o prazer obtido durante e após a produção. À medida que a associação se formaliza, propõe a coletivização da produção. Em muitos casos, a diretriz adquirida durante os cursos de capacitação ofertados pelo Sebrae é de que a produção seja otimizada por meio da divisão do trabalho, seguindo uma lógica de linhas de produção, em que cada artesão confecciona apenas uma parte do produto todo, que deve ser montado em série - o que garantiria maior oferta de produtos e preços mais baixos, e consequentemente maiores lucros, a serem divididos entre os vários autores das peças comercializadas.

Essas diretrizes da produção propiciaram aos artesãos da associação, em 2008, a conquista do Prêmio Top 100 do Sebrae, que acontece quadrienalmente e possibilita aos ganhadores expor e comercializar, sem custos, suas peças em diversas feiras pelo Brasil afora. Já que a produção era feita de forma coletiva, o prêmio foi concedido à associação como um todo. Essa conquista ampliou a visibilidade de seus produtos em nível nacional, mas também gerou divergências de opiniões entre os associados, já que nem todos puderam ter seus produtos expostos e comercializados nas feiras.

Muitos artesãos alegam que essa divisão do trabalho nem sempre é feita de forma equilibrada, há sempre alguém que produz mais que os demais, ou que trabalha em mais frentes, impedindo uma divisão justa dos lucros e dos méritos. Do mesmo modo, alegam que tal lógica produtiva não gera motivação em produzir, já que não há autoria nas peças produzidas, impossibilitando o sentimento de satisfação e orgulho de ver uma peça pronta, ou de criar um novo produto. Após esse descontentamento e de muitas discussões na gestão da produção, a associação decide então não mais interferir na produção dos artesanatos e pas- 
sa a atuar apenas como revendedora dos produtos de seus associados. Para tanto, retém 10\% do lucro para as vendedoras e para a manutenção do local, e cobra de cada membro uma taxa inicial de cinquenta reais e mensal de seis reais.

A produção, então, volta a ser individualizada, ou familiar, como em muitos casos. Logo, cada artesão deixa seus produtos consignados na associação, e quando são vendidas as peças recebem o mesmo valor estabelecido, deduzida a comissão estipulada. Os custos com a mensalidade e a comissão fizeram com que alguns artesãos não se tornassem membros da associação, como é o caso da filha de Dona Miúda, Detô, que produzia e comercializava individualmente antes mesmo do surgimento da Associação dos Artesãos de Capim-Dourado Pontealtense. Ela também não participou dos cursos do Sebrae, continuando a produção tradicional do artesanato que aprendera com sua mãe.

Em outros casos, os associados mantêm sua filiação com a associação, mas realizam vendas sem os vínculos associativos e, desse modo, ficam com todo o lucro da venda. Há associados que praticam essa venda em suas próprias residências, outros criaram blogs e/ou sites próprios, outros ainda abriram sua própria loja e oficina de artesanato. Essa abertura do mercado aumenta o poder de barganha dos compradores, o que diminui o preço dos produtos, pela alta competitividade. Além disso, permite a ação de "atravessadores", que compram o artesanato e mesmo a matéria-prima por um preço muito baixo e revendem a comerciantes de Palmas, que supervalorizam os preços. Apesar de não impedir esse tipo de atuação, a associação fica temerosa com seu enfraquecimento e perda do poder de barganha, como afirma o atual presidente, Edgar Aires Pimenta.

Esse novo modelo de produção possibilitou que um número maior de artesãos comercializasse seus produtos e conseguisse se inserir em práticas de consumo antes vistas como inacessíveis. Além de se tornarem empresários, muitos puderam adquirir casa própria (ou reformar), automóvel, televisão, telefone, computador, entre tantos outros bens que não constituíam parte de suas cotidianidades antes da valorização do capim-dourado.

Além da associação, outros 16 artesãos de Ponte Alta exportaram em 2012 na faixa de até um milhão de dólares, conforme dados da Secretaria da Fazenda do Estado do Tocantins e da Secretaria de Comércio Exterior (SECEX) - órgão específico do Ministério do Desenvolvimento, Indústria e Comércio Exterior. O Prêmio Top 100 do Sebrae 2012 foi concedido, dessa vez, a apenas um dos artesãos do Jalapão, Valtair Daniel, que se destacou pela sua produção criativa e inovadora. Esse artesão, após presidir a associação, decidiu montar seu próprio ateliê, que conta com um espaço aconchegante e moderno. Comercializa seus produtos internacionalmente por intermédio de sua loja virtual. No entanto, continua como membro atuante da associação e, sempre que possui um pedido grande, redistribui a demanda para os melhores artesãos associados, já que a qualidade é uma de suas marcas registradas.

Com a disseminação do conhecimento artesanal, muitos compradores de Palmas passaram a comprar dos "atravessadores" o capim em estado de matéria-prima e a confeccionar suas próprias peças. Esse movimento gerou a diminuição do capim- dourado explorado à revelia e em grande quantidade e também estacionou o comércio do artesanato na associação, porém foi logo coibido pelas autoridades - pressionadas pelos artesãos do Jalapão - por meio da Portaria 092/2005, do Instituto ${ }^{5}$ Natureza do Tocantins (Naturatins).

Essa Portaria se baseia no conhecimento secular das comunidades do Jalapão sobre a extração sustentável do capim-dourado e determina que apenas as hastes podem ser colhidas, após 20 de setembro, sendo que as flores (capítulos ou frutos) devem ser cortadas e dispersas no solo logo após a colheita, possibilitando a germinação de novas plantas. Ademais, a Portaria proíbe que as hastes de capim-dourado saiam da região in natura, podendo apenas ser comercializadas em forma de artesanato. Essas regras visam garantir a produção de sementes (que ocorre apenas a partir do início de setembro) e sua manutenção nos campos úmidos, para que as populações de capim-dourado possam se manter naturalmente. Além disso, pretende-se garantir que o capim-dourado gere renda para artesãos da região do Jalapão, sendo vendido já como artesanato, com valor agregado.

No entanto, à medida que o conhecimento sobre o manejo com tal matéria-prima se dissemina, surgem novas habilidades que desafiam a associação. Recentemente, um dos artesãos, com o fim de agilizar sua produção, criou uma máquina que permite a junção do capim em hastes enroladas por fios de cobre. Essas hastes são utilizadas especialmente na produção de bijuterias e semijoias (Figura 3), mas essa iniciativa teve um efeito colateral. Tanto as máquinas quanto as hastes passaram a ser comercializadas à revelia. Como não constituem artesanato, e sim um tipo de manufatura, o preço cai à medida que cresce a produção. Muitos compradores das hastes são moradores de Pal-

5. No terceiro mandato do governo do estado, por meio da Lei n. 858, de 26 de julho de 1996, a Fundação Natureza do Tocantins, que tinha como competência promover a pesquisa e o estudo na área de controle e proteção ambiental, é substituída pelo Instituto Natureza do Tocantins, que passa a executar, monitorar e fiscalizar políticas públicas voltadas para as questões ambientais. Disponível em: <www.naturatins.to.gov.br/ institucional/a-instituicaos. 
mas que as utilizam como matéria-prima para a confecção de artesanatos e outros produtos, concorrendo com o artesanato do Jalapão e contrariando a Portaria da Naturatins, que visava coibir essa concorrência.

A solução encontrada pela associação, temerosa com a perda de mercado e da identidade do capim associada ao Jalapão, é ampliar a Portaria 092/2005, acrescentando determinações que impeçam tanto a venda das máquinas quanto das hastes, que podem ser desmontadas e reutilizadas em estado in natura (Figura 5, acima). A tramitação desse processo encontra-se em fase de diálogo entre a associação e as autoridades locais. Outra solução é a produção de um selo que garanta que a peça de artesanato seja originária do Jalapão e confeccionada com capim extraído de forma sustentável, respeitando a maturação e renovação da planta, como indica a Portaria estadual. Esse pedido de indicação geográfica (IG) e indicação de procedência (IP) do artesanato confeccionado à mão, com capim-dourado da região do Jalapão, foi realizado pela Associação de Artesãos em Capim-dourado da Região do Jalapão (AREJA) junto ao Instituto Nacional da Propriedade Industrial (INPI). A AREJA representa as nove associações, distribuídas em oito municípios do Jalapão - Ponte Alta do Tocantins, São Félix do Tocantins, Lizarda, Santa Tereza do Tocantins, Lagoa do Tocantins, Novo Acordo, Rio Sono e Mateiros (que possui uma associação no centro urbano e outra no quilombo de Mumbuca) -, e conta com cerca de 3000 artesãos cadastrados.

Embora o selo de indicação geográfica tenha sido concedido em agosto de 2011 pelo INPI, ainda não está sendo utilizado, em razão de brigas políticas locais. Segundo depoentes de Ponte Alta, como Valtair Daniel, há forte interesse dos comerciantes de Palmas em impedir sua utilização, já que o selo desvalorizaria a produção feita fora do circuito do Jalapão. Ainda que, como afirma Yúdice (2006), o gerenciamento desse campo de forças performativas deva buscar legitimar os grupos, ações e representações num quadro de ressignificação identitária, agenciando a autonomia e empoderamento dos envolvidos, de forma não hierárquica, tampouco totalizadora, a inserção no mercado tende a gerar a hierarquização e a individualização competitiva. Os conflitos em torno da propriedade intelectual sobre o artesanato de capim-dourado e sobre os direitos de extração da matéria-prima são elucidativos dessa hierarquização e individualização competitiva de que fala Yúdice (2006). Além disso, há uma divergência sobre a adequação das peças produzidas de acordo com os procedimentos estabelecidos para obtenção do referido selo, como indica Ana Claudia Matos da Silva, presidente da AREJA.

De todo modo, o reconhecimento institucional concedido aos artesãos jalaponenses em forma de prêmios, editais e portarias - por parte dos governos municipal, estadual e federal, e também por parte de entidades privadas e filantrópicas que visam proteger suas tradições e gerar possibilidades de participação no mercado - indica que não mais prevalece o modelo que desconsidera as identidades particulares dos indivíduos em prol de identidades nacionais e políticas. Como indica Lopes (2012), portanto, não existe mais isonomia do direito, já que a hegemonia consensual passa a ser inclusiva. No caso dos jalaponenses, tanto a Portaria da Naturatins quanto o pedido de propriedade intelectual feito ao INPI, por exemplo, se tornam tecnologias sociais de inclusão, proteção de direitos e ampliação de cidadania, baseadas na originalidade e autenticidade de suas tradições e identidade, fundadas em saberes seculares.

Logo, apesar da competição por esse mercado promissor, o reconhecimento identitário por meio do artesanato do capim-dourado demonstra que há aceitação estatal e mercadológica em relação às tradições desses artesãos. Sua inserção social, política e econômica possibilita a satisfação de sua cidadania, pelo menos no tocante ao consumo, já que, como afirma Canclini (2001), na globalização atual muitas perguntas dos cidadãos são respondidas mais pelo consumo privado de bens e dos meios de comunicação de massa do que pelas regras abstratas da democracia ou da participação coletiva em espaços públicos. Isso porque o consumo não é meramente um ato irracional ou um gasto desnecessário, é sim um espaço onde se reorganiza parte da racionalidade econômica, política e psicológica social.

\section{Considerações finais}

Após a abolição da escravatura, o destino tomado pelos afrodescendentes foi diverso. Muitos foram absorvidos pela indústria de massa, no contexto das grandes cidades; outros decidiram retornar à África, retorno este que fora incentivado pelas autoridades nacionais; muitos outros procuraram refúgios em áreas isoladas, como nos antigos quilombos, ou permaneceram nos arredores das grandes fazendas, onde podiam dar continuidade à sua agricultura de subsistência. O projeto de construção da nação brasileira não esteve preocupado com o destino desse contingente de afrodescendentes e indígenas, a menos que constituíssem mão de obra para a crescente indústria na zona urbana do país, que se limitava à região sudeste. No Centro-Oeste e na região Norte, muitos desses grupos de camponeses traçaram seu próprio destino à margem das ambições nacionais, reproduzindo formas próprias de identidade e sociabilidade, embasados em suas próprias tradições, crenças e sa- 
beres adquiridos de seus ancestrais e de sua relação com o território e com os recursos naturais próprios do cerrado.

No âmbito das cidades dos entornos, onde a racionalidade civilizatória se infiltrava por meio da gestão burocrática, que em muitos casos convivia com as práticas reinventadas do coronelismo clientelista brasileiro de antanho, tais grupos tradicionais percebiam a diacronia de seu modo de vida, ao mesmo tempo que tinham acesso às novas diretrizes racionalistas. A distinção social entre os diferentes grupos durante os contatos ora levava à desvalorização de sua cultura e de suas práticas sociossimbólicas (por isso sentiam vergonha dos chapéus feitos de capim-dourado), ora reafirmava a fricção étnica e o consequente apego à sua identidade específica, como ocorreu com Dona Miúda e seus familiares, que se recusam a deixar seu território e a abandonar seus costumes, apesar dos constrangimentos da sociedade inclusiva e das dificuldades do estilo de vida mantido por esse grupo de negros tradicionais, agora reconhecidos como "quilombolas".

No caso do quilombo de Mumbuca, é justamente o artesanato do capim-dourado o catalisador do reconhecimento da identidade territorial do grupo, pautado em diretrizes multiculturais, seguindo o ícone étnico-quilombola. Essa abertura e resgate de formas de vida que um dia foram promulgadas como extintas pelo ideal progressista de construção da nação ocorrem devido a uma nostalgia romântica, motivada pela carência e ausência dessa ruralidade autêntica na rotina ultratecnológica das cidades. Isso porque, ao agenciar desencaixes e reencaixes entre tempo e espaço, retirando a transcendentalidade da cultura e substituindo o vácuo deixado por símbolos massificados e patrimônios da humanidade, o processo de globalização atual, fundado sobre o intenso fluxo técnico-informacional, gera uma alta produtividade do novo e um constante descarte de classificações de fórmulas, que geram insegurança e incerteza. Tal sentimento, por sua vez, desperta o retorno à tradição, a um tempo mítico e originário em que tais aflições ainda não assolavam a psique humana.

É desse modo que as identidades específicas, bem como os grupos e comunidades fundados em saberes tradicionais e seculares, conseguem se objetivar para além de suas fronteiras territoriais, especialmente aqueles cuja organização local consegue formar um novo mercado, cuja essência está na reatualização do passado no presente, como ocorre com as associações de artesãos do capim dourado, mesmo que contem com a ajuda de "agentes da modernidade". Isso porque, para o Estado e para o mercado, essa se torna uma possibilidade para que a cultura funcione como complementação do desenvolvimento econômico, sem, no entanto, perder sua suposta autenticidade, desperdiçar as competências criativas de seus produtores.

Esse advento, pela abertura ao mercado, se torna também extensivo aos demais grupos citadinos, que embora adotassem um estilo de vida urbano e rejeitassem a identidade quilombola, tem sua história marcada pelo estigma do atraso e pelas tradições e recursos da zona rural do entorno, protagonizados por seus antepassados afro-indígenas e pela morosidade das cidades do interior. Além disso, por entenderem melhor as demandas dos consumidores do artesanato e terem maior acesso às instituições governamentais e da sociedade civil que apoiam tais empreendimentos, os artesãos citadinos, como os de Ponte Alta, conseguem, com muita criatividade, novos recursos e saberes tecnológicos, modernizar a técnica secular, inovando e diversificando os produtos, aumentando sua produção e distribuição de forma a atender às necessidades, às conveniências e ao gosto estético e imediatista de seus consumidores. Nesse sentido, o acesso à internet se torna crucial para os empreendedores de Ponte Alta.

A atuação da associação, bem como de órgãos públicos, privados e comunitários, na emancipação do artesanato do capim-dourado demonstra que a comunicação entre as culturas advindas do processo de globalização e mundialização acirra um processo de descontinuidade cultural. Esse processo medeia a significação dos discursos maciços e seus usos sociais, enfatiza a cultura popular a partir da memória territorial, mas também acirra conflitos identitários e lógico-formais. Logo, as lógicas modernas de competição, de extração e distribuição dos recursos naturais, e de gestão da produtividade e da comercialização desse produto artesanal conflitam com as práticas e motivações tradicionais de produção e com a autenticidade da identidade local desse saber secular.

Podemos perceber então que a força performativa desses conflitos identitários faz com que a cultura se torne um recurso que gera e atrai investimentos, especialmente por meio da propriedade intelectual, tornando-se um novo vetor para o desenvolvimento local e nacional. Esse é o argumento que alimenta a crescente economia criativa, cuja expectativa é acirrar o desenvolvimento econômico e turístico local, contribuindo para a riqueza nacional. 


\title{
Referências
}

ALVES, E. P. M. A economia criativa do Brasil: modernização cultural, criação e mercado. Dossiê: Cultura e Desenvolvimento - o advento da economia criativa. Revista Latitude, v. 6, n. 2, Ed. UFal, 2012.

BOURDIEU, P. A distinção: crítica social do julgamento. São Paulo/Porto Alegre: Edusp/Zouk, 2007.

CANCLINI, N. G. Políticas culturais na América Latina. Novos Estudos CEBRAP, São Paulo, v. 2 , n. 2, p. 39-51, jul. 1993.

Consumidores e cidadãos: conflitos multiculturais da globalização. Rio de Janeiro: UFRJ, 2001.

FERNANDES, F. Capitalismo dependente e classes sociais na América Latina. Rio de Janeiro: Jorge Zahar, 1972.

FRIEDMAN, M. Capitalismo e liberdade. São Paulo: Nova Cultural, 1985.

HABERMAS, J. Mudança estrutural da esfera pública. Rio de Janeiro: Tempo Brasileiro, [1962]1984.

HOWKINS, J. The creative economy: how people make money from ideas. Londres: Penguin Books, 2001.

LIFSCHITZ, J. A. Comunidades tradicionais e neocomunidades. Rio de Janeiro: Contracapa/FAPERJ, 2011.

LOPES, J. R. As ações culturais coletivas e o questionamento do campo normalizador dos direitos. In: LOPES, J. R.; MELO, J. L. B. de; GADEA, C. A. (Orgs.). Periferias, territórios e saberes. São Leopoldo, RS: Óikos/
FAPERGS/CAPES, 2012. p. 51-68.

MARTIN-BARBERO, J. Ofício de cartógrafo: travessias latino-americanas da comunicação na cultura. São Paulo: Edições Loyola, 2004.

MARTINS, J. D. S. A exclusão social e a nova desigualdade. São Paulo: Paulus, 1997.

ORTIZ, R. Mundialização e cultura. São Paulo: Brasiliense, 2003.

RICOEUR, P. Tempo e narrativa. Campinas, SP: Papirus, 1993.

ROUANET, S. P. Mal-estar na modernidade. São Paulo: Companhia das Letras, 1993.

SANTOS, A. S. S. Patrimônio e memória: da imposição de identidades à potencialização de atos coletivos. In: RUBIM, A. A. C.; ROCHA, R. (Orgs.). Políticas culturais. Salvador: EDUFBA, 2012.

SANTOS, B. de S. (Org.). Globalização: fatalidade ou utopia? Porto: Afrontamento, 2002.

TAYLOR, C. As fontes do self. São Paulo: Edições Loyola, 1997.

Multiculturalimo: examinando a política de reconhecimento. Lisboa: Instituto Piaget, 1998.

YÚDICE, G. A conveniência da cultura: usos da cultura na era global. Belo Horizonte: Ed. UFMG, 2006.

\section{Modernity and cultural diversity: the limit is the market - a case study on the golden grass crafts in Jalapão}

\begin{abstract}
This paper turns around a case study on the social and identity conflicts among the actors involved in the golden grass craft production, in the region of Jalapão (TO), Brazil. The national and international success of golden grass handicrafts reflects the return to traditional and cultural appreciation, which can be understood as an attempt to fill the vacuum left by the loss of cultural transcendentalism in the disembedding environment of the actual globalized modernity. Such collisions allow us to understand how the cultural and identity appreciation by the market can mean the welfare of the golden grass artisans by overcoming the peripheral inclusion in the economy. Despite of provoking new conflicts, this valorization stimulates the local development.
\end{abstract}

Key words: local development, creative economy, modernity and cultural diversity. 


\section{La modernidad $y$ diversidad cultural: el límite es el mercado - un estudio de caso sobre las artesanías de hierba de oro en Jalapão}

\section{Resumen}

En este trabajo se analiza cómo el actual anacronismo de la identidad, que define un ambiente de diversidad cultural después de frustrar la linealidad racionalista de la modernidad, en lugar de activar la decadencia de este codicioso sistema universal rearticula sus parámetros, a través del mercado y de las conectividades técnico informacionales. El análisis se centra en un estudio de caso sobre los conflictos sociales y de identidad entre los actores involucrados en la producción de artesanías de hierba de oro, en la región de Jalapão, en Tocantins. El éxito de la artesanía de hierba de oro, tanto nacional como internacional, refleja el retorno a las tradiciones y a los valores culturales, el cual puede entenderse como un intento de llenar el vacío dejado por la pérdida de la trascendentalidad de la cultura en el contexto de desatraque de la modernidad globalizada de hoy. Tales enfrentamientos nos ayudan a entender cómo la valoración de la cultura y de la identidad del mercado puede significar la satisfacción de la dignidad y el bienestar de los artesanos de la hierba de oro al superar la inclusión periférica en la economía e impulsar el desarrollo local, mientras desencadena nuevos conflictos.

Palabras clave: desarrollo local, economía creativa, modernidad y diversidad cultural.

Data de recebimento do artigo: 18/9/2013

Data de aprovação do artigo: 19/8/2014 